\title{
Effects of alpine swamp wetland change on rainfall season runoff and flood characteristics in the headwater area of the Yangtze River
}

\author{
Jia Li ${ }^{\mathrm{a}, \mathrm{c}}$, Wenjiao Shi ${ }^{\mathrm{b}, *}$ \\ a State Key Laboratory of Desert and Oasis Ecology, Xinjiang Institute of Ecology and Geography, Chinese Academy of Sciences, Urumqi 830011, China \\ ${ }^{\mathrm{b}}$ Key Laboratory of Land Surface Pattern and Simulation, Institute of Geographical Sciences and Natural Resources Research, Chinese Academy of Sciences, Beijing 100101, PR China \\ c University of Chinese Academy of Sciences, Beijing 100049, China
}

\section{A R T I C L E I N F O}

\section{Article history:}

Received 23 June 2014

Received in revised form 10 December 2014

Accepted 11 December 2014

Available online 31 December 2014

Keywords:

Alpine swamp wetland change

Rainfall season runoff

Flood characteristics

Headwater area of Yangtze River

\begin{abstract}
A B S T R A C T
The effects of changes in alpine swamp wetland (ASW) on rainfall season runoff and flood characteristics have not been quantified adequately in the headwater area of the Yangtze River (HYR).To address this, we focus on detecting changes in ASW based on remote sensing data. In particular, we analyzed the effects of ASW on runoff (both runoff and runoff coefficient) and flood characteristics (i.e., peak flow, rising time, duration and flood runoff coefficient) during the rainfall season based on observed runoff and climate data. Our results indicate that the area of ASW decreased by $28.22 \%$ and $30.54 \%$ at Zhimenda (ZMD) and Tuotuohe (TTH), respectively, from 1975 to 2004. Moreover, 76\% and 71\% of the decreases at ZMD and TTH, respectively, occurred during the period from 1990 to 2004. Both runoff and the runoff coefficients decreased at ZMD and increased at TTH with decreasing ASW in the rainfall season; we attribute this to the variability in runoff mechanisms. The effects of ASW on runoff and runoff coefficients were more pronounced at ZMD than at TTH. A slightly lower maximum peak flow and a greater frequency of moderate and small peak flows were observed at ZMD. Conversely, maximum peak flow increased and the frequency of maximum and moderate peak flows increased at TTH. Flood events increased at both ZMD and TTH, whereas both the rising time and duration decreased at both sites. Overall, the volume of snowmelt water increased and the ability to conserve water decreased in response to decreased ASW and permafrost were responsible for the observed changes in flood characteristics.
\end{abstract}

(C) 2014 Elsevier B.V. All rights reserved.

\section{Introduction}

Alpine swamp wetlands (ASW), which are dominated by alpine swamp meadows, are particularly dense in the headwater area of the Yangtze River (HYR) (Zhang et al., 2011). Typically, hydrological conditions determine both the attributes and spatial distribution of wetlands, while wetlands themselves influence the water cycles and hydrological processes of regions and basins, respectively (Price and Schlotzhauer, 1999; Price and Waddington, 2000; Reeve et al., 2000). Global climate change has affected natural ecosystems significantly worldwide, particularly wetland ecosystems, whose sensitivity to global climate change has accelerated their degradation (Bullock and Acreman, 2003; Rodriguez-Iturbe, 2000; Wassen and Grootjans, 1996). However, the link between changes in alpine swamp wetland and the river hydrological process has not been adequately investigated and quantified.

\footnotetext{
* Corresponding author at: Institute of Geographic Sciences and Natural Resources Research, Chinese Academy of Sciences, 11A, Datun Road, Anwai, Beijing 100101, China. Tel.: +8610 64888890; fax: +861064854230.

E-mail address: shiwj@lreis.ac.cn (W. Shi).
}

Owing to climate change, discharge from rivers in HYR has varied significantly (Wang et al., 2007, 2009, 2012a; Zhang et al., 2011). The runoff process is complex; according to recent studies, runoff in HYR is typically influenced by snow and glacier melt, the frozen soil cycle, and changes in alpine grassland and alpine swamp wetland systems (Gao et al., 2012; Wang et al., 2001, 2007, 2009; Zhang et al., 2003, 2011). However, the mechanisms by which runoff is related to hydrological processes at the watershed scale remain unclear owing to sparse data coverage and limited hydrological model development (McClelland et al., 2004; Yamazaki et al., 2006). Moreover, although ASW is the most important alpine wetland in HYR (Wang et al., 2007; Zhang et al., 2011), few studies have documented changes in this wetland type in response to climatic change (Wang et al., 2007; Zhang et al., 2011);accordingly, the effects of ASW change in particular on hydrological processes in HYR remains unclear.

ASW in HYR can be considered to be a type of upland rain-fed wetland, defined according to Acreman and Holden (2013), owing to its location and hydrological characteristics. Acreman and Holden (2013) reviewed the influences of such rain-fed wetlands in headwater watersheds and redefined the flood characteristics resulting from these wetlands. As such, their study offered a new approach for the identification 
of the effects of ASW change on flood characteristics in HYR. In addition, several studies describing hydrological process in HYR have been published in recent years (Wang et al., 2007, 2009, 2012a). The results of these studies demonstrated that rainfall season runoff was determined primarily by precipitation throughout HYR (Wang et al., 2009, 2012a). Moreover, as completely thawing of frozen soil, ASW played a vital role in both surface and subsurface hydrological processes (Wang et al., 2009, 2012a).Therefore, it is critical to detect the effect of ASW change on runoff and flood characteristics in the rainfall season in HYR. To address this, the present study investigates changes in ASW in HYR from 1975 to 2004 based on remote sensing data. In particular, we aim to determine the effects of ASW change on runoff and flood characteristics during the rainfall season based on observations from meteorological and hydrologic stations.

\section{Material and methods}

\subsection{Study area}

The headwater area of the Yangtze River (HYR) watershed covers an area of $13.78 \times 10^{4} \mathrm{~km}^{2}$ and is an upper tributary of the Yangtze River, located in the northeast of the Qinghai-Tibet plateau $\left(90^{\circ} 43^{\prime}-\right.$ $97^{\circ} 31^{\prime} \mathrm{E}$ and $32^{\circ} 30^{\prime}-35^{\circ} 35^{\prime} \mathrm{N}$ ) (Fig. 1). The altitude of HYR is in the range 3523-6590 $\mathrm{m}$ a.s.l., with an average elevation of $4759 \mathrm{~m}$ a.s.l.

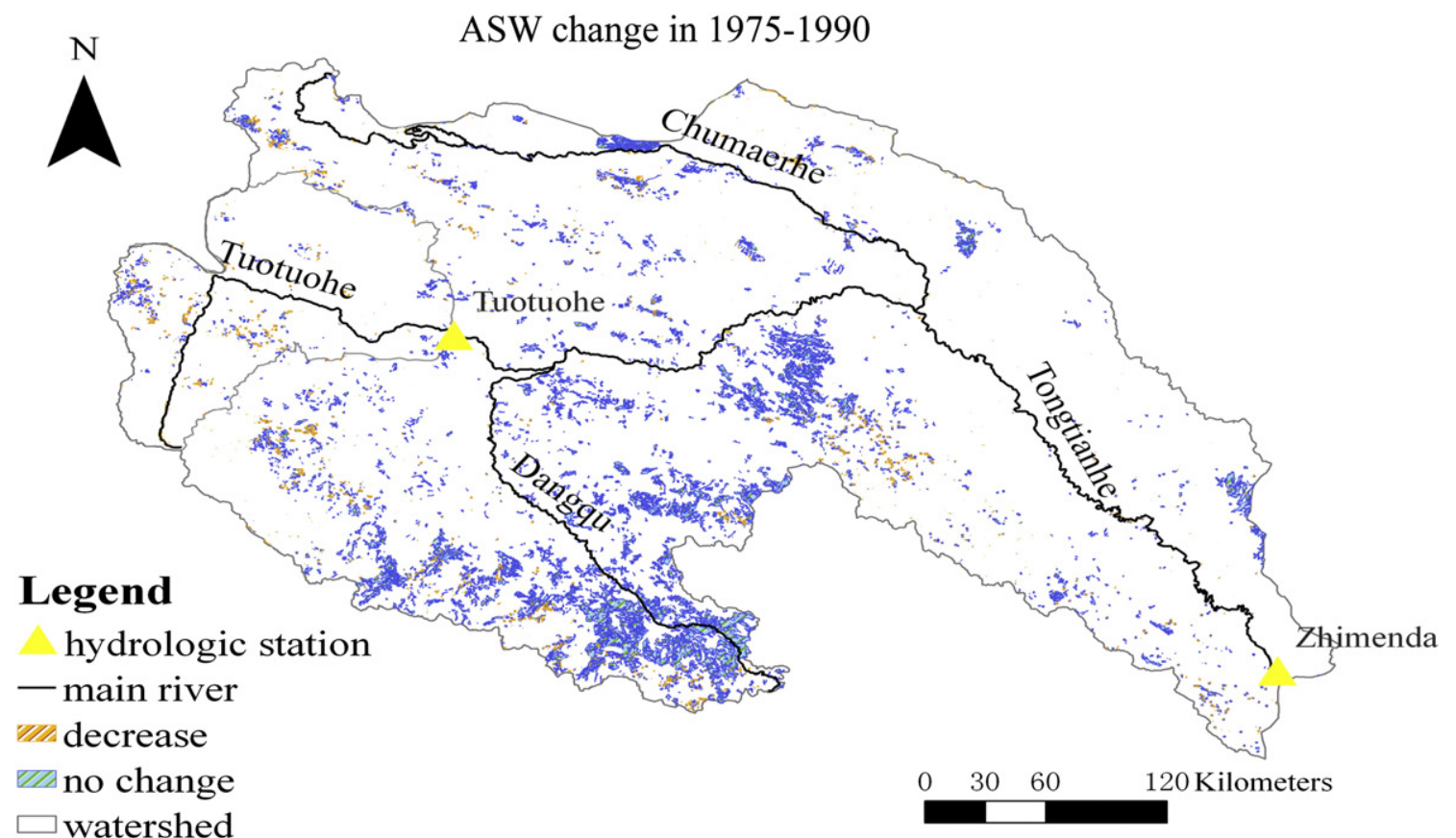

ASW change in 1990-2004

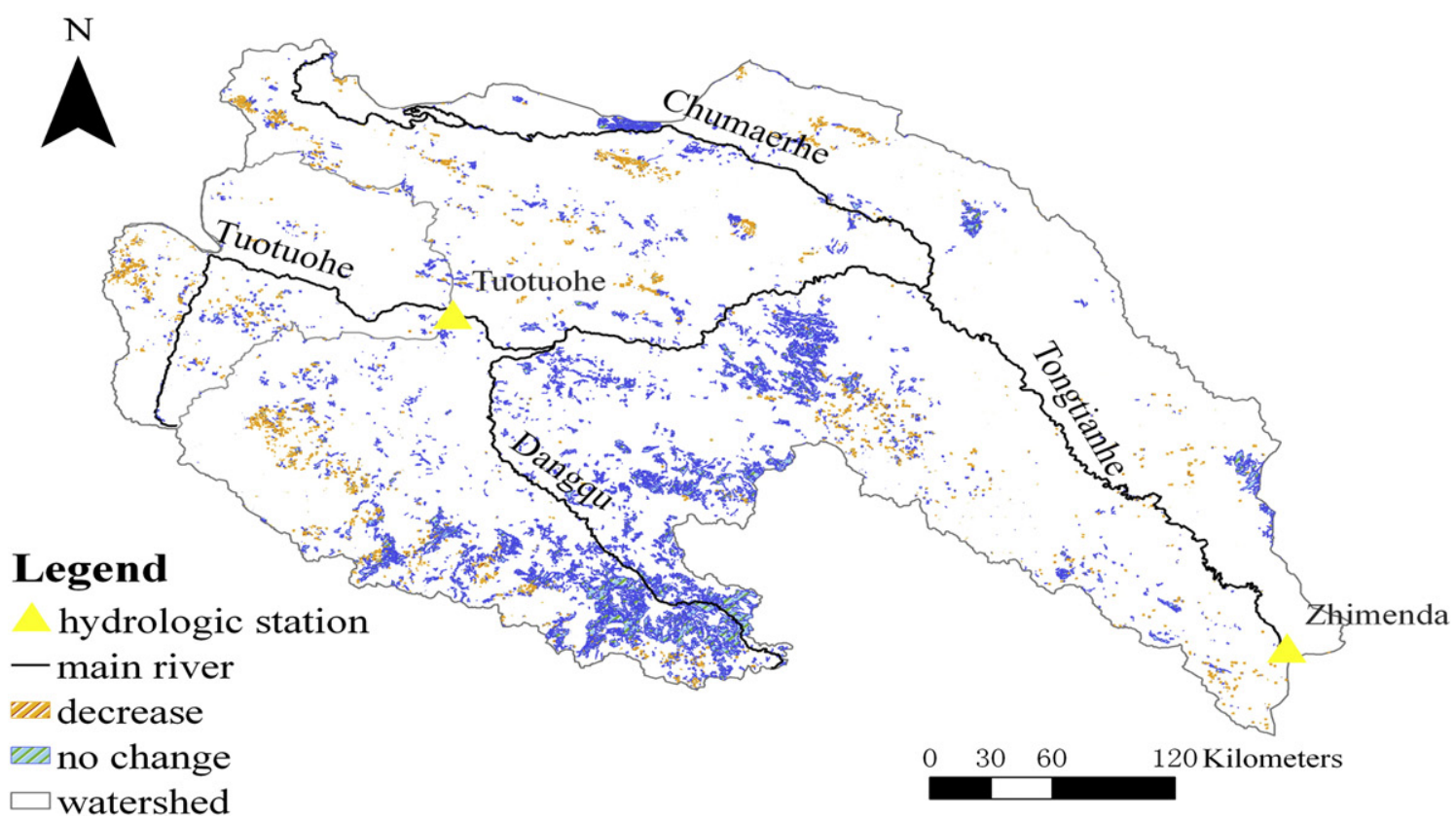

Fig. 1. Decrease of ASW in ZMD and TTH with two periods. 
Alpine swamp wetlands, dominated by alpine swamp meadows, are most concentrated in the headwater region of the Yangtze River. The dominant swamp vegetation species in HYR include Kobresia tibetica Maxim. and Carex tibetica Franch (Li and Zhou, 1998; Wang et al., 2001). The mean annual temperature ranges from $-1.7^{\circ} \mathrm{C}$ to $-5.5^{\circ} \mathrm{C}$, and mean annual precipitation is in the range of $270-410 \mathrm{~mm}$ (Wang et al., 2001, 2006a).

There are four main rivers in HYR: the Tuotuohe, Dangqu, Chumaerhe, and Tongtianhe. The runoff depth (determined based on water and heat conditions; Wang et al., 2001) decreases from southeast to northwest, with depths of $150.1,92.8,55.2$, and $49.9 \mathrm{~mm}$ in the Dangqu, Tongtianhe, Tuotuohe, and Chumaerhe rivers, respectively (Fig. 1).The observed hydrological station at Tuotuohe $\left(92.43^{\circ} \mathrm{E}\right.$, $34.21^{\circ} \mathrm{N}$ ) controls runoff in the upper area of the Tuotuohe River, whereas that at Zhimenda $\left(97.25^{\circ} \mathrm{E}, 32.98^{\circ} \mathrm{N}\right)$ is located at the outlet of HYR and reflects the overall characteristics of all four rivers (Fig. 1).

\subsection{Data sources}

We obtained hydrological data (1975-2004) for the rainfall season (June 11 to September 30) water discharges from two stations in HYR (TTH and ZMD).Each data set contained the daily values from 1975 to 2004. In the study region, meteorological stations are sparse and typically located at relatively low altitudes (Yang et al., 2007). Four meteorological data sets from meteorological stations in the Tuotuohe, Wudaoliang, Yushu, and Qumalai regions were selected. Owing to good agreement among the four stations, variations in air temperature at these stations were assumed to be representative of changes in air temperature throughout the entire region. However, precipitation at these four stations is likely not representative of that at higher altitudes owing to strong local variability (Yang et al., 2007). Thus, monthly and average rainfall season values of precipitation and air temperature were analyzed in the present study. We consider these values to be representative of regional climate change characteristics based on previous studies (Li et al., 2009; Yang et al., 2007; Zhang et al., 2011).

Three Landsat Thematic Mapper (TM) or Multi-Spectral Scanner (MSS) images of HYR for the 1970s, 1990s, and 2004 were used to extract alpine swamp wetland areas at our study site (Liu et al., 2008). The spatial resolution of MSS digital images is $80 \mathrm{~m}$ for the mid-to late 1970s; that of TM is $30 \mathrm{~m}$ for the 1990s and 2004. A series of image processing steps were undertaken in the ERDAS Image and ArcInfo software packages for the three time periods. Based on field data and a 1:100,000 topographic base map, raw data were subjected to a series of treatments including TM[MSS] radiation calibration, geometric rectification, Universal Transverse Mercator (UTM) geographical coordinate image rectification and topographic map $(1: 100,000)$ rectification. Visual interpretation of remote sensing imagery was used in this study. A remote sensing interpretation mark database consisting of 400 mark points of 25 types was established on the basis of field surveys. The preliminary classification results were therefore revised according to visual interpretation and ground survey, to reduce any noise caused by mixed scattered point features. We also resampled three periods of remote sensing maps (1970s, 1990s, and 2004) with a spatial resolution of $100 \mathrm{~m}$ and extracted ASW for dynamic change analysis.

\subsection{Analysis methods}

Numerous previous studies have examined changes in the runoff regime or peak flow based on runoff and climate data (e.g., Archer, 2003, 2007; Archer and Newson, 2002; Archer et al., 2010; Komatsu, 2011). In the present study, we also used observed runoff and climate data to detect the effects of ASW on rainfall season runoff and flood characteristics. It may be the useful way to identify the problem.

To analyze ASW change, we compared spatiotemporal shifts in ASW and the variation in extent of land cover attributable to ASW, using $R_{\text {asw }}$ to represent the rate of variation with time and $p_{\text {asw }}$ to represent the extent of variation across subregions (ZMD and TTH) (Liu et al., 2003; Wang et al., 2006a,b; Zhang et al., 2011):

$p_{\text {asw }}=100 \times\left[\left(\mathrm{LU}_{\mathrm{ASWt} 1}-\mathrm{LU}_{\mathrm{ASWt} 0}\right) / \mathrm{LU}_{\mathrm{ASWt} 0}\right]$

$R_{\mathrm{asw}}=p_{\mathrm{asw}} \times \frac{1}{\mathrm{~T}}$

Here, $\mathrm{LU}_{\mathrm{ASW} \text { to }}$ and $\mathrm{LU}_{\mathrm{ASWt} 1}$ denote the area of ASW in the study region at the start and end of the study period, respectively, and $\mathrm{T}$ represents the length of the study period.

Hydrologists do not define a flood simply in terms of land inundated, but as a significant increase in river discharge (Haarhoff and Cassa, 2009). Flood analysis is undertaken using annual maximum flows, although the maximum flow in any given year does not necessarily result in a flood in which water has overtopped the river channel (Acreman and Holden, 2013). In this context, Acreman and Holden (2013) defined river discharge over time during a flood event based on a number of characteristics; they also explained how upland rainfed wetland can influence upstream flood processes.

In the present study, we identified the following flood characteristics with reference to Acreman and Holden (2013). (1) The peak flow determines the maximum flood level and the extent of inundation. (2) The rising time indicates how fast the flood water rises; thus, it indicates how quickly the flood reaches its peak and how much time is available to avoid it. (3) The duration indicates how long the flood lasts. In the present study, flood duration was divided into single-precipitation flood (SPF) and multiple-precipitation flood (MPF) groups, where SPFs and MPFs corresponded to durations of 1-6 days and $>6$ days, respectively. (4) The flood runoff coefficient (FRC) represents the ratio of the volume of precipitation to flood runoff during each flood event. We believe that these characteristics adequately reflect the effects of ASW hydrological function on flood characteristics. In addition, regression analyses were performed to identify the relationships between rainfall season runoff, precipitation and temperature, and linear regression analyses were used to describe temporal trends in these three parameters (Wang et al., 2012b).

\section{Results}

\subsection{Decrease in ASW}

Fig. 1 illustrates the distribution of and decrease in ASW in HYR for 1975-1990 (period I) and 1990-2004 (period II), whereas Table 1 presents the temporal area and rate changes in ASW for each period. ASW covered approximately $6793.21 \mathrm{~km}^{2}$ in 1975 , representing $4.9 \%$ of HYR, with $64 \%$ of ASW distributed at heights of $4500-4800 \mathrm{~m}$ and $8 \%$ above $\mathrm{TTH}$. In response to changes in climate and other environmental factors, the area of ASW had decreased to $4876.35 \mathrm{~km}^{2}$ by 2004, indicating a decrease of $28.22 \%$ ( $0.94 \%$ year $^{-1}$ ) for all of HYR from 1975 to 2004 ; this represents decreases of $21.65 \%$ (1.44\% year $\left.{ }^{-1}\right)$ and $8.39 \%(0.56 \%$ year $^{-1}$ ) for periods II and I, respectively. A similar decrease was found for TTH: ASW decreased by 30.54\% (1.02\% year ${ }^{-1}$ ) from 1975 to 2004, with $11.09 \%$ (0.74\% year $\left.^{-1}\right)$ and $21.87 \%$ (1.46 year $\left.^{-1}\right)$ decreases in periods I and II, respectively. In particular, the most pronounced decrease

Table 1

Decrease of ASW in the ZMD and TTH.

\begin{tabular}{llccc}
\hline Subbasin & Time period & $p_{\text {asw }}(\%)$ & $R_{\text {asw }}(\%)$ & Total area $\left(\mathrm{km}^{2}\right)$ \\
\hline TTH & $1975-1990$ & -11.09 & -0.74 & -60.31 \\
& $1990-2004$ & -21.87 & -1.46 & -105.67 \\
\multirow{3}{*}{ ZMD } & $1975-2004$ & -30.54 & -1.02 & -165.98 \\
& $1975-1990$ & -8.39 & -0.56 & -569.54 \\
& $1990-2004$ & -21.65 & -1.44 & -1347.32 \\
& $1975-2004$ & -28.22 & -0.94 & -1916.86 \\
\hline
\end{tabular}


was observed in the Tongtianhe main stream and the southeast area of HYR, and the rate of decrease was found to be faster during Period II. This result agrees with results reported previously by Zhang et al. (2011), who examined decreases in coverage of wetland ecosystems in the headwater regions of the Yangtze and Yellow rivers and the nearby Zoige region during 1967-2000. In particular, Zhang et al. (2011) reported ASW to cover $7452.67 \mathrm{~km}^{2}$ in 1967 and just $5191.85 \mathrm{~km}^{2}$ in 2000 , corresponding to decreases of $28.87 \%$ and $96 \%$ during the periods 1967-2000and 1986-2000, respectively.

\subsection{Variation in the relationship between precipitation and runoff under decreasing ASW}

During the rainfall season, precipitation and daily runoff were observed at the meteorological stations and hydrological stations (1975-2004). Fig. 2 illustrates the observed relationship between precipitation density and runoff for the two hydrological stations in controlled watersheds during two periods of ASW decrease (1975-1990 and 1990-2004). At ZMD, the relationship between runoff and precipitation fit aquadratic function that explained more than $67 \%$ of the variance and exhibited a statistically significant relationship $(p<0.01)$ under decreasing ASW (Fig. 2a). However, at TTH, a significant linear relationship explained more than $37 \%$ of the variance ( $<<0.01$ ) (Fig. 2b).

The relationships between precipitation and runoff at TTH and ZMD were found to be different under the same precipitation density conditions. At ZMD, the runoff decreased by $10.5 \%$ when precipitation was
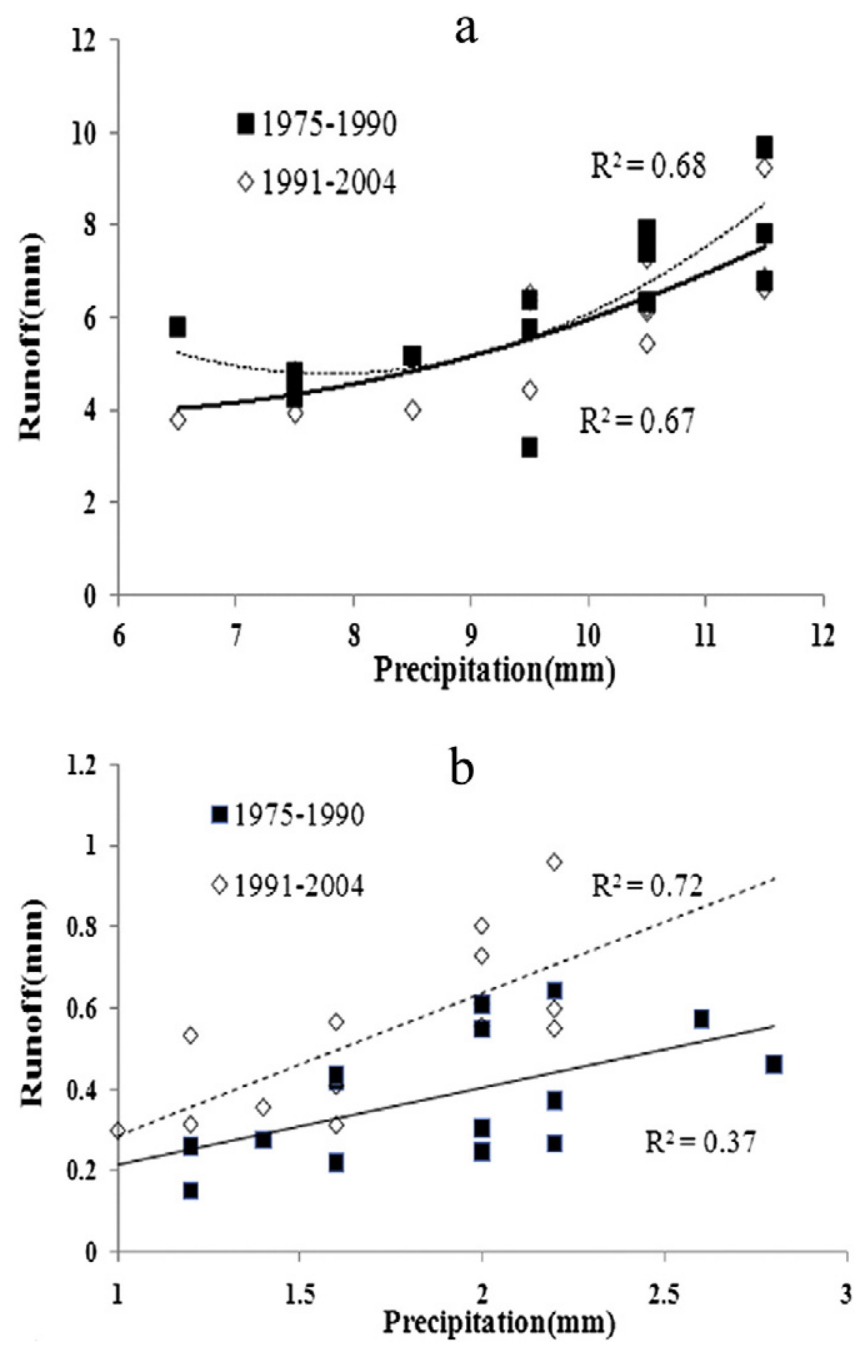

Fig. 2. Rainfall-runoff relationship under decrease of ASW in (a) ZMD and (b) TTH. greater than $10 \mathrm{~mm}$ and by $10.4 \%$ for rainfall lower than $8.5 \mathrm{~mm}$, based on the degree of reduction from $8.39 \%$ (period I) to $21.65 \%$ (period II). In addition, runoff remained constant for precipitation density in the range 8.5-10 mm (Fig. 2a). Conversely, runoff increased by $42.1 \%$ for all precipitation densities in response to reductions of $11.09 \%$ (period I) and $21.87 \%$ (period II) at TTH (Fig. 2b).

We categorized the recorded precipitation data into each four classes at TTH and ZMD (Table 2) and calculated the average runoff coefficients for each class. The runoff coefficient at ZMD was far greater than that at TTH for the same period. Moreover, the runoff coefficient at ZMD decreased with decreasing ASW: the average runoff coefficient was $65.5 \%$ and $60.5 \%$ in periods I and II, respectively. The variation in runoff coefficients exhibits a $\mathrm{V}$ shape with increasing precipitation class (i.e., from 5-7 mm to $11-13 \mathrm{~mm}$ ) in period I but a linear increase with increasing precipitation class (i.e., from 5-7 $\mathrm{mm}$ to $11-13 \mathrm{~mm}$ ) in period II. In contrast, at TTH, the runoff coefficient increased with decreasing ASW: the average runoff coefficients in periods I and II were $20.1 \%$ and $31.5 \%$, respectively. Additionally, there was no linear increase in runoff coefficient with increasing precipitation (from $1-1.5 \mathrm{~mm}$ to $2.5-3 \mathrm{~mm}$ ) at TTH during period I, although the runoff coefficient did increase linearly with precipitation (from 1-1.5 $\mathrm{mm}$ to 2.5-3 mm) during period II (Table 2). These results indicated that ASW played different roles in governing precipitation and runoff at ZMD and TTH in the rainfall season.

\subsection{Peak flow dynamics under decreasing ASW}

Flood events were investigated statistically based on the runoff data from two hydrologic stations. To analyze the peak flow characteristics, we classified the peak flow into four levels at both TTH and ZMD. Fig. 3 illustrates the frequency of peak flow at both stations for two selected periods (1975-1990 and 1990-2004). At ZMD, the average flow was $943.4 \mathrm{~m}^{3} / \mathrm{s}$ and $828.9 \mathrm{~m}^{3} / \mathrm{s}$ during periods I and II, respectively. The peak flow occurred primarily during at levels of $1000-3000 \mathrm{~m}^{3} / \mathrm{s}$ during period I, which represented approximately $93 \%$ of all flood events. When ASW decreased from $8.39 \%$ to $21.65 \%$ (i.e., from period I to II; Table 1 ), the frequency of peak flow increased by $42 \%$, and peak flow occurred primarily under levels of $2000 \mathrm{~m}^{3} / \mathrm{s}$. Moreover, the frequency of peak flow at levels below $2000 \mathrm{~m}^{3} / \mathrm{s}$ increased by $100 \%$ from period I to period II, and no peak flows greater than $3000 \mathrm{~m}^{3} / \mathrm{s}$ were detected during period II. Thus, it can be concluded that the frequency of flood only increased for peak flow under $2000 \mathrm{~m}^{3} / \mathrm{s}$ between periods I and II.

At TTH, the average flow was $55.2 \mathrm{~m}^{3} / \mathrm{s}$ and $84.8 \mathrm{~m}^{3} / \mathrm{s}$ for periods I and II, respectively. The peak flow occurred primarily at levels below $300 \mathrm{~m}^{3} / \mathrm{s}$ during period I, accounting for approximately $96.9 \%$ of all flood events. When ASW decreased from $11.09 \%$ to $21.87 \%$ (i.e., from period I to period II), the frequency of peak flow increased by $87 \%$, and peak flows occurred primarily at levels of $100-300 \mathrm{~m}^{3} / \mathrm{s}$. Moreover, the frequency of peak flows at levels of 100 to $300 \mathrm{~m}^{3} / \mathrm{s}$ increased by $114 \%$ from period I to period II. There was also an increase (decrease) in peak flow at levels above $300 \mathrm{~m}^{3} / \mathrm{s}$ (below $100 \mathrm{~m}^{3} / \mathrm{s}$ ) between periods I and II. Generally, flood events can be considered to have increased at peak flow above $100 \mathrm{~m}^{3} / \mathrm{s}$ and decreased at peak flow below $100 \mathrm{~m}^{3} / \mathrm{s}$.

Table 2

Comparison of the runoff ratios in TTH and ZMD under two periods (mean value, \%).

\begin{tabular}{|c|c|c|c|c|c|c|c|c|c|}
\hline \multirow[t]{2}{*}{ TTH } & \multicolumn{4}{|c|}{ Precipitation (mm) } & \multirow[t]{2}{*}{ ZMD } & \multicolumn{4}{|c|}{ Precipitation (mm) } \\
\hline & $1-1.5$ & $1.5-2$ & $2-2.5$ & $2.5-3$ & & $5-7$ & $7-9$ & $9-11$ & $11-13$ \\
\hline & 17.9 & 22.3 & 20.5 & 19.4 & $1975-1990$ & 72.5 & 60.5 & 63.1 & 70.3 \\
\hline 1990-2004 & 32.1 & 30.7 & 31.8 & 34.6 & 1990-2004 & 58.6 & 57.2 & 60.3 & 65.9 \\
\hline
\end{tabular}



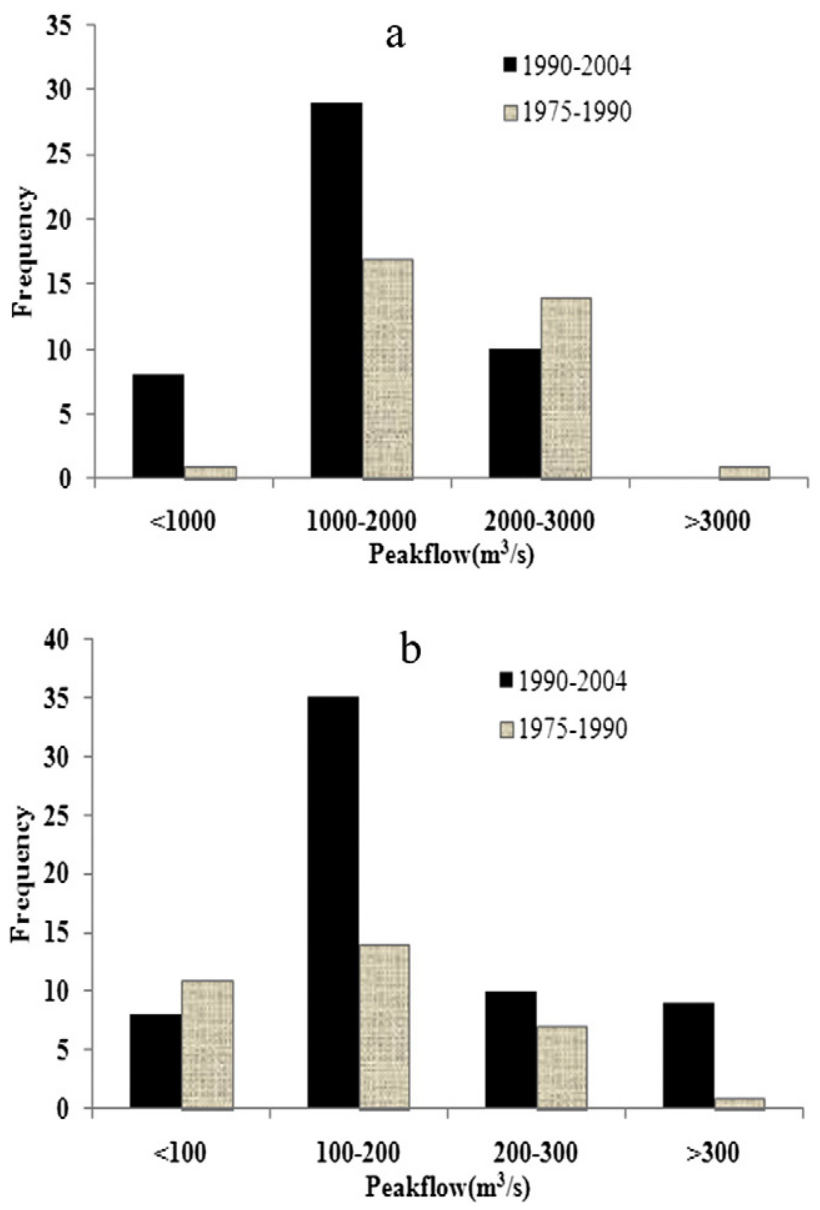

Fig. 3. Frequencies of peak flow in (a) ZMD and (b) TTH.

\subsection{Change in flood duration, rising time and FRC under decreasing ASW}

The frequency of SPFs increased by 1-5 times at ZMD; conversely, that at TTH increased by 6 times during period I and 13 times during period II. Moreover, the average rising time of SPFs declined from 2.3 to 1.8 and the duration of SPFs decreased from 5.6 to 5.2 from period I to period II at TTH. At MPF, the duration was in the range 8-27 days for both periods at ZMD, where the average duration was 17.6 (15.3) days and the average rising time was7.7 (6.2) days during period I (period II). At TTH, the duration of MPFs was 7-24 (7-22) days during period I (period II); the average duration was 13.8 (12.4) days, and the average rising time was 7.1 (6.1) days in period I (period II). These results indicate that both the average rising time and duration of MPFs decreased from period I to period II at both TTH and ZMD.

Table 3 presents changes in the frequency of rising time and duration of MPFs at ZMD and TTH. In particular, an increase (decrease) in the frequency of durations less than (more than) 20 days and a decrease in levels of above 20 days was observed from period I to period II at ZMD. Similar results were found at TTH. For rising time, we observed an increase (decrease) in the frequency of values under (over) 7 days between periods I and II at ZMD. At TTH, we observed an increase (decrease) in the frequency of values under (over) 12 days between periods I and II.

At ZMD, a total of 33 flood events occurred during period I. For 25 of these, we obtained FRCs $<1$, with an average value of 0.64 ; the remaining 8 FRCs were $>1$, with an average value of 1.17. In contrast, 47 flood events occurred during period II. For 37 of these, the FRCs were $<1$, with an average value of 0.58 ; the FRCs for the remaining 10 were $>1$, with an average value of 1.21 . At TTH, there were 33 flood events during period
Table 3

Change of frequency in rising time and duration of MPF in ZMD and TTH.

\begin{tabular}{|c|c|c|c|c|c|}
\hline & \multirow[b]{2}{*}{ Class (day) } & \multicolumn{2}{|c|}{ Frequency-ZMD } & \multicolumn{2}{|c|}{ Frequency-TTH } \\
\hline & & 1975-1990 & 1990-2004 & 1975-1990 & 1990-2004 \\
\hline & $<10$ & 1 & 7 & 5 & 12 \\
\hline \multirow[t]{2}{*}{ Duration } & $10-20$ & 21 & 28 & 18 & 34 \\
\hline & $>20$ & 10 & 7 & 4 & 3 \\
\hline \multirow[t]{3}{*}{ Rising time } & $3-7$ & 18 & 30 & 21 & 34 \\
\hline & $8-12$ & 12 & 11 & 4 & 14 \\
\hline & $>12$ & 2 & 1 & 2 & 1 \\
\hline
\end{tabular}

I, and all FRCs were $<1$, with an average value of 0.30 . However, 62 flood events were detected during period II. Of these, 36 FRCs were $<1$, with an average value of 0.58 , and the remaining 26 had FRCs $>1$ (average: 1.72 ).

\section{Discussion}

\subsection{Reasons for decreasing ASW}

Climate factors (Song et al., 2012), soil type and topography (Skole et al., 1994), and human activity (Zalidis et al., 1997) have all been considered as factors affecting wetland change. Previous studies have indicated that wetland area is correlated strongly with growing season air temperature $(R=0.73, P \leq 0.001)$ and relatively weakly with mean annual air temperature $(R=0.43, P=0.044)$ in HYR. In contrast, wetland area is correlated more weakly with annual precipitation $(R=0.25, P=0.38)$ and mean growing season precipitation $(R=0.32$, $P=0.19$ ) (Zhang et al., 2011). The strong wetland area and air temperature relationships demonstrate that the alpine wetlands in HYR would have been influenced strongly by air temperature changes, particularly during the vegetation growing season. Between 1975 and 2004, the region's mean annual air temperature rose by $0.38^{\circ} \mathrm{C}$ decade ${ }^{-1}$, while the growing season air temperature increased by $0.44{ }^{\circ} \mathrm{C}$ decade ${ }^{-1}$; however, over the same period, the precipitation remained stable or increased only slightly. Such increases in temperature can lead to increased potential evapotranspiration, thus decreasing relative humidity and resulting in the emergence of a tendency toward dryness. In addition, a significant statistical correlation has been found between vegetative cover and the thickness of the active soil layer of permafrost in alpine meadow and alpine swamp meadow ecosystems (Wang et al., 2006a,b; Zhao et al., 2000; Zhou, 2001). In particular, as the thickness of the active layer increases, the vegetative cover of alpine swamp (including alpine meadows) decreases. Over the last 30 years, the warming climate has increased the temperature of the upper layer (i.e., 0-0.40 m) of the Qinghai-Tibetan plateau's permafrost soils by $0.2-0.3{ }^{\circ} \mathrm{C}$ (Wang, 1998; Wu et al., 2001), leading to the gradual disappearance of permafrost (Wang et al., 2001; Zhao et al., 2000). This degradation of the permafrost has, in turn, significantly affected alpine swamp wetland ecosystems in HYR. Thus, in general, the increasing temperature and changes in the thickness of the active layer through thawing of frozen soil can be considered major contributions to the decrease in ASW.

\subsection{Rainfall season runoff mechanisms at TTH and ZMD}

The observed decrease in ASW exhibited spatiotemporal variations throughout HYR; in particular, greater decreases occurred during period II than period I. Moreover, for the same rainfall season precipitation, decreased ASW led to decreased runoff at ZMD but increased runoff at TTH (Fig. 3; Table 2).We attribute this primarily to different runoff generation mechanisms between the two sites. Typically, in addition to ASW, factors such as vegetation cover changes, permafrost changes, and glacier and snow melt can contribute to rainfall season runoff. We posit that the observed differences between ZMD and TTH can be attributed to differential inputs of these contributing factors. 
At TTH, $81 \%$ of annual precipitation and $78 \%$ of annual total runoff occurred in the rainfall season during 1975-2004; however, the average runoff coefficient was $24 \%$ during the rainfall season at this site. We also analyzed the relationships between runoff and climate factors (temperature and precipitation) using a regression method. The results demonstrate that runoff was related linearly to temperature, with significant growth trends in both runoff and temperature at TTH (Fig. 4b), while precipitation remained relatively constant. As the temperature increased, snow and glacier melt would also have increased, thus increasing runoff; this explains the correspondence between the temperature and runoff trends. These results suggest that runoff was determined largely by snow and glacier melt and temperature during the rainfall season, and Wang et al. (2007) determined that approximately 33.7\% of runoff was produced by snow and glacier melt at TTH. In addition, ASW had a small capacity to absorb precipitation in the rainfall season. While it had a larger capacity to generate runoff due to the saturation water content of surface soil (Acreman and Holden, 2013; Holden et al., 2011; Price, 1992). Therefore the rainfall season runoff could decrease under the
ASW decrease owing to an increase quantity of water entering into the surface soil layer. The slight runoff decrease at TTH caused by ASW decrease was limited in reducing the runoff in rainfall season which was mainly amplified by snow and glacier melt. Accordingly, the observed increases in runoff coefficients were likely controlled primarily by increases in glacier melting under the warming conditions at TTH.

At ZMD, $72 \%$ of annual total runoff and $74 \%$ of annual precipitation occurred in the rainfall season (1975-2004), and the average runoff coefficient was $66 \%$ during the rainfall season. The linear regression coefficient for runoff and precipitation was greater than that for runoff and temperature. In fact, temperature exhibited a linear increase, while precipitation and runoff exhibited no increasing trend (Fig. 4a), suggesting that changes in runoff were linked more closely to changes in precipitation than in temperature at this site. The observed decrease in runoff coefficients at ZMD likely occurred in response to a combination of the synergistic effects of permafrost degradation, snowmelt change, and vegetation cover and ASW decrease (Wang et al., 2007). Of these factors, the changes in both the thickness of the active
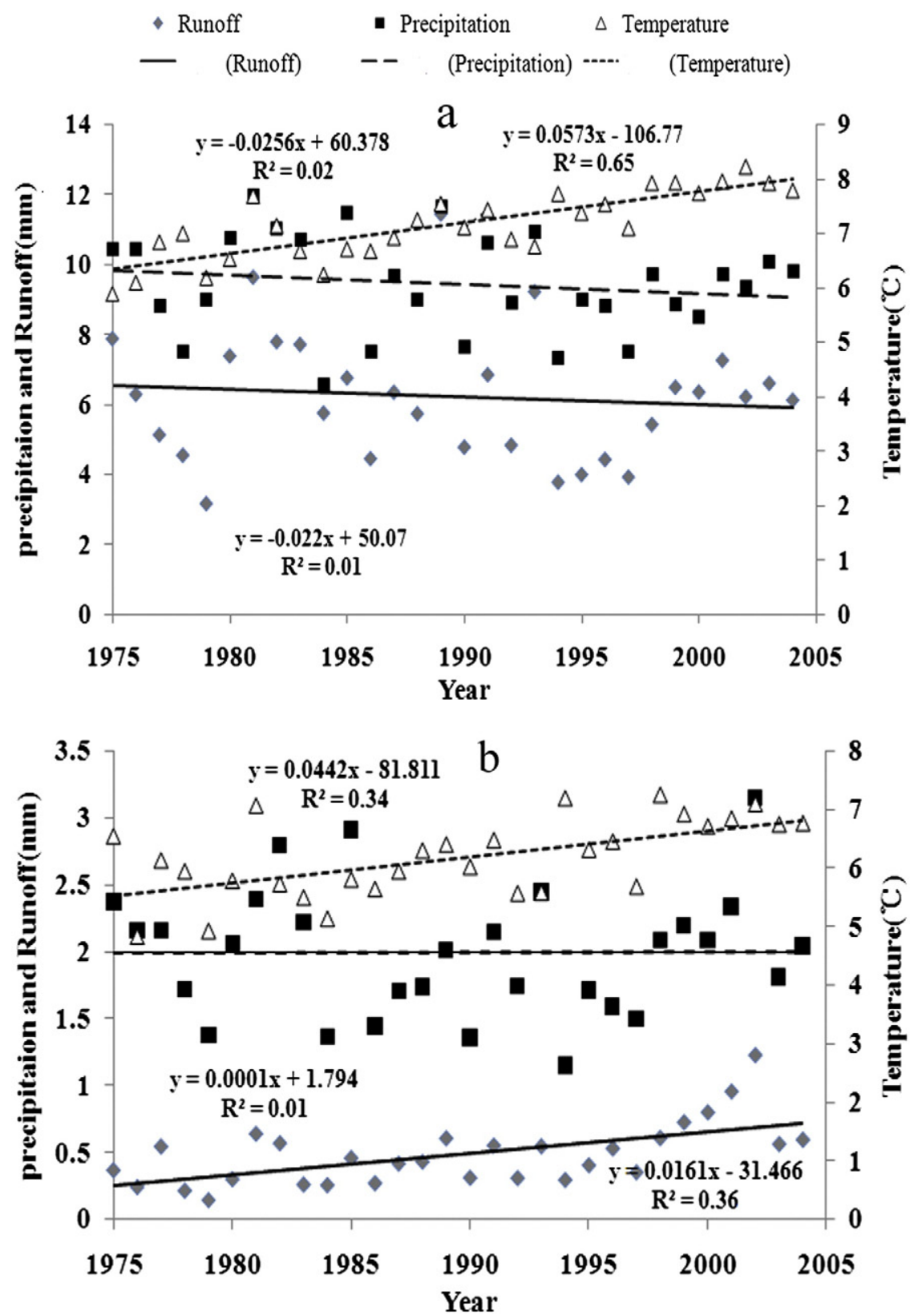

Fig. 4. Trend of rainfall runoff, precipitation, and temperature in (a) ZMD and (b) TTH. 
soil layer of permafrost and ASW at ZMD were important for rainfall season runoff. The thickness of the active soil layer of permafrost likely increased in the rainfall season owing to the increased temperatures observed. Consequently, the soil would have received more water from incoming precipitation, resulting in decreased runoff. In addition, the rainfall season runoff also further decreased in ZMD by ASW decrease owing to ASW generating the runoff in the headwater regions as its saturation water content of surface soil (Acreman and Holden, 2013). Consequently, the runoff coefficient could have decreased when precipitation density remained relatively constant from period I to period II at this site. We believe that these different runoff generation mechanisms can explain the observed variability in runoff coefficient under decreasing ASW at two different sites.

\subsection{Effects of decreasing ASW on flood characteristics}

We found the extent of ASW decrease to be similar at ZMD and TTH (see Section 3.1), although flood characteristics during the rainfall season varied between the two sites even as ASW decreased. Peak flow and frequencies at both the maximum and middle levels increased at TTH, whereas the maximum peak flow decreased and the frequencies at the middle and low levels of peak flow increased at ZMD (Fig. 3). Peak flow determines the maximum flood level and is related to the ability of runoff generation, precipitation, and hydrological function of ASW. At ZMD, precipitation has varied little during the rainfall season throughout the last 30 years (Fig. 4a), yet ASW has decreased dramatically; the hydrological function of ASW has also been reduced accordingly. In addition, the ability of runoff generation decreased owing to rainfall season runoff and runoff coefficient decrease. As a result, under the same incoming water volume (precipitation) at ZMD, the maximum peak flow decreased as the ability of runoff generation decreased and the middle and low levels of peak flow increased due to the hydrological function deficit introduced by the reduction in ASW. At TTH, increased snow and glacier melt were clearly the dominant factors controlling rainfall season runoff and flood. As the temperature increased during the rainfall season over the past 30 years (Fig. $4 \mathrm{~b}$ ), the volume of incoming water increased by snow and glacier melt. In addition, the ability of runoff generation also increased in TTH (rainfall season runoff and runoff coefficient increase). Therefore, peak flow and frequencies at both the maximum and middle levels increased at TTH.

Flood events increased by $42 \%$ at ZMD and $89 \%$ at TTH from period I to period II. The majority of these additional flood events were MPFs, with a few SPFs, at both ZMD and TTH. The amounts of precipitation were slightly different in ZMD and TTH (Fig. 4). Therefore, increases in MPFs and SPFs at TTH were associated with temperature and snowmelt water increase from period I to period II at this site. While increase of MPF and SPF at ZMD were likely associated primarily with weakening of ecosystem hydrological conservation due to the sharp decrease in ASW, permafrost and alpine meadow at this site. In addition, the rising time and duration of MPFs decreased at both ZMD and TTH. The duration and peak flow determined the volume (total amount of water in the flood) based on river flood hydrograph introduced by Acreman and Holden (2013) (Page 774-775). The duration change was related to the change of peak flow and volume. In this study, both the volume and peak flow decreased in ZMD from period I to period II. As a result, the duration of MPF decreased in ZMD. However, the volume increased by only $4 \%$ and peak flow increased by about $28 \%$ in TTH from period I to period II. Therefore, the duration of MPF also decreased in TTH.

\section{Conclusions}

Wetlands play an important role in the hydrological cycle, influencing groundwater recharge, low flows, evaporation, and floods. ASW can be considered a type of upland rain-fed wetland. The effects of ASW on rainfall season runoff process and flood characteristics were previously unknown in HYR. To address this, the present study investigated the relationship between ASW change and rainfall season runoff processes and flood characteristics using statistical and regression approaches at the watershed scale. In particular, we analyzed ASW change using satellite remote sensing data for the 1970s, 1990s, and 2004. Moreover, we studied changes in rainfall season runoff and flood characteristics in association with ASW decrease in HYR.

The main findings were as follows. ASW decreased by $28.22 \%$ (1.02\% year $^{-1}$ ) from 1975 to 2004 at ZMD, with the majority of the decrease occurring between 1990 and 2004. Although the extent of ASW decrease was similar for both TTH and ZMD, the runoff processes and flood characteristics varied between the two sites in rainfall season. For example, runoff and the runoff coefficient increased at TTH and decreased at ZMD, even under the same precipitation density. We attribute these changes to differences in runoff generation mechanisms between the two sites. In particular, we attribute the decrease in runoff coefficients at ZMD to a combination of the synergistic effects of permafrost degradation, snowmelt change, and vegetation cover and ASW decrease. Conversely, the increased runoff coefficients at TTH were due primarily to snowmelt water. Moreover, the effects of ASW on rainfall season runoff and runoff coefficients were much more pronounced at ZMD than at TTH.

We also suggest that water conservation decrease due to ASW decrease, snowmelt increase, and degradation of grassland and permafrost played a vital role in changing the flood characteristics at our study sites. At ZMD, the maximum peak flow $\left(>3000 \mathrm{~m}^{3} / \mathrm{s}\right)$ decreased little over the period 1990-2004, during which time ASW decreased by more than during 1975-1990. Conversely, at TTH, the maximum peak flow increased over the period 1990-2004. Moreover, the frequency at the middle and lower levels of peak flow increased at ZMD, whereas the maximum and middle levels of peak flow increased at TTH. Flood events (both SPFs and MPFs) increased at both ZMD and TTH, although the rainfall season runoff did not increase at ZMD (Fig. 4a) and increased only slightly at TTH (Fig. 4b). The rising time and duration both decreased at TTH and ZMD. Finally, FRCs $>1$ increased at and FRCs $<1$ decreased at ZMD, whereas all FRCs increased at TTH. Based on these FRC changes, it is clear that the density of flood increased.

Our study used only observed data to detect the effects of ASW change on rainfall season runoff and flood characteristics at the watershed scale. Rational analysis has been used often in previous studies of this type; however, quantitative analysis of the effects of ASW change on rainfall season runoff and flood characteristics could not be achieved using such methods. Nevertheless, a distributed hydrological model would offer a useful means of identifying the physical hydrologic processes associated with ASW in watersheds. Accordingly, further research will be required to introduce such a model to simulate how wetland change affects flood characteristics.

\section{Acknowledgements}

This research was funded by the National Natural Science Foundation of China (41371002 and 91325204), and the "Strategic Priority Research Program" of the Chinese Academy of Sciences, Climate Change: Carbon Budget and Relevant Issues (XDA05090310). We are grateful to the editor of CATENA and to the reviewers for their valuable suggestions.

\section{Appendix A. Supplementary data}

Supplementary data associated with this article can be found in the online version, at http://dx.doi.org/10.1016/j.catena.2014.12.020. These data include Google map of the most important areas described in this article.

\section{References}

Acreman, M., Holden, J., 2013. How wetlands affect floods. Wetlands 33, 773-786.

Archer, D.R., 2003. Scale effects on the hydrological impact of upland afforestation and drainage using indices of flow variability: the River Irthing, England. Hydrol. Earth Syst. Sci. 7, 325-338 
Archer, D.R., 2007. The use of flow variability analysis to assess the impact of land use change on the paired Plynlimon catchments, mid-Wales. J. Hydrol. 347, 487-496.

Archer, D.R., Climent-Soler, D., Holman, I.P., 2010. Changes in discharge rise and fall rates applied to impact assessment of catchment land use. Hydrol. Res. 41, 13-26.

Archer, D.R., Newson, M.D., 2002. The use of indices of flow variability in assessing the hydrological and instream habitat impacts of upland afforestation and drainage. J. Hydrol. 268, 244-258.

Bullock, A., Acreman, M., 2003. The role of wetlands in the hydrological cycle. Hydrol. Earth Syst. Sci. 7, 358-389.

Gao, H.K., He, X.B., Ye, B.S., Pu, J.C., 2012. Modeling the runoff and glacier mass balance in a small watershed on the Central Tibetan Plateau, China, from 1955 to 2008. Hydrol. Process. 26, 1593-1603.

Haarhoff, J., Cassa, A., 2009. Introduction to flood hydrology. Juta Legal and Academic Publishers, Amsterdam.

Holden, J., Wallage, Z.E., Lane, S.N., McDonald, A.T., 2011. Water table dynamics in drained and restored blanket peat. J. Hydrol. 402, 103-114.

Komatsu, H., Shinohara, Y., Kume, T., Otsuki, K., 2011. Changes in peak flow with decreased forestry practices: Analysis using watershed runoff data. J. Environ. Manag. 92, 1528-1536.

Li, W., Zhou, X., 1998. Ecosystems of Qinghai-Tibetan plateau and approach for their sustainable management. Guangdong Science \& Technology Press, Guangzhou.

Li, S.N., Wang, G.X., Deng, W., Hu, Y.M., Hu, W.W., 2009. Influence of hydrology process on wetland landscape pattern: A case study in the Yellow River Delta. Ecol. Eng. 35 1719-1726.

Liu, J., Liu, M., Zhuang, D., 2003. Study on spatial pattern of land-use change in China during 1995-2000. Sci. China. Ser. D Earth Sci. 46 (4), 373-384.

Liu, J.Y., Xu, X.L., Shao, Q.Q., 2008. Grassland degradation in the "Three-River Headwaters" region, Qinghai Province. J. Geogr. Sci. 18, 259-273.

McClelland, J.W., Holmes, R.M., Peterson, B.J., Stieglitz, M., 2004. Increasing river discharge in the Eurasian Arctic: Consideration of dams, permafrost thaw and fires as potential agents of change. J. Geogr. Res. 109, 98-102.

Price, J.S., 1992. Blanket bog in Newfoundland: Part 2. Hydrological processes. J. Hydrol. $135,103-119$.

Price, J.S., Schlotzhauer, S.M., 1999. Importance of shrinkage and compression in determining water storage changes in peat: The case of a mined peatland. Hydrol. Process. 13, 2591-2601.

Price, J.S., Waddington, J.M., 2000. Advances in Canadian wetland hydrology and biogeochemistry, 1995-1998. Hydrol. Process. 14, 1579-1589.

Reeve, A.S., Siegel, D.I., Glaser, P.H., 2000. Simulating vertical flow in large peatlands. J. Hydrol. 227, 207-217.

Rodriguez-Iturbe, I., 2000. Ecohydrology: A hydrological perspective of climate, soil and vegetation dynamics. Water Resour. Res. 36, 3-9.

Skole, D.L., Chomentowski, W.H., Salas, W.A., Nobre, A.D., 1994. Physical and human dimensions of deforestation in, Amazonia. Bioscience 44, 314-322.
Song, K.S., Wang, Z.M., Li, L., Tedesco, L., Li, F., Cui, J., Du, J., 2012. Wetlands shrinkage, fragmentation and their links to agriculture in the MulengeXingkai Plain, China. J. Environ. Manag. 111, 120-132.

Wang, G.X., Li, Q., Cheng, G., 2001. Climate change and its impact on the ecoenvironment in the source regions of Yangtze and Yellow Rivers in recent 40 years. J. Glaciol. Geocryol. 23, 346-352.

Wang, G.X., Li, Y., Chen, L., 2006a. Impacts of permafrost changes on alpine ecosystem in Qinghai-Tibetan plateau. Sci. China. Ser. D Earth Sci. 49 (11), 1156-1169.

Wang, G.X., Liu, J., Chen, L., 2006b. Comparison of spatial diversity of land use changes and the impacts on two typical areas of Heihe River Basin. Acta Geograph. Sin. 61 (4), 339-348.

Wang, G.X., Li, Y., Wang, Y., Shen, Y., 2007. Impacts of alpine ecosystem and climatic changes on surface runoff in the source region of Yangtze River. J. Glaciol. Geocryol. 29, 159-168

Wang, G.X., Hu, H.C., Li, T.B., 2009. The influence of freeze-thaw cycles of active soil layer on surface runoff in a permafrost watershed. J. Hydrol. 375, 438-449.

Wang, G.X., Liu, G.S., Li, C.J., 2012a. Effects of changes in alpine grassland vegetation cover on hillslope hydrological processes in a permafrost watershed. J. Hydrol. 444-445, 22-33.

Wang, G.X., Liu, G.S., Liu, L., 2012b. Spatial scale effect on seasonal stream flows in permafrost catchments on the Qinghai-Tibet Plateau. Hydrol. Process. 26, 973-984.

Wang, S., 1998. Discussion on the permafrost degradation and the changes of the permafrost environment of Qinghai-Xizang plateau [in Chinese with English abstract]. J. Adv. Earth Sci. 13 (Suppl.), 65-73.

Wassen, W.J., Grootjans, A.P., 1996. Ecohydrology: An interdisciplinary approach for wetland management and restoration. J. Veg. 126, 1-4.

Wu, Q., Li, X., Li, W., 2001. The response model of permafrost along the Qinghai-Tibetan Highway under climate change [in Chinese with English abstract]. J. Glaciol. Geocryol. 23 (1), 1-6.

Yamazaki, Y., Kubota, J., Ohata, T., Vuglinsky, V., Mizuyama, T., 2006. Seasonal changes in runoff characteristics on a permafrost watershed in the southern mountainous region of eastern Siberia. Hydrol. Process. 20, 453-467.

Yang, J.P., Ding, Y.J., Chen, R.S., 2007. Climatic causes of ecological and environmental variations in the source regions of the Yangtze and Yellow Rivers of China. Environ Geol. 53, 113-121.

Zalidis, G.C., Mantzavelas, A.L., Gourvelou, E., 1997. Environment impacts on Greek wetlands. Wetlands 17, 339-345.

Zhang, Y., Ohata, T., Kadata, T., 2003. Land surface hydrological processes in the permafrost region of the eastern Tibetan Plateau. J. Hydrol. 283, 41-56.

Zhang, Y., Wang, G.X., Wang, Y.B., 2011. Changes in alpine wetland ecosystems of the Oinghai-Tibetan plateau from 1967 to 2004. Environ. Monit. Assess. 180, 189-199.

Zhao, L., Chen, G., Cheng, G., 2000. Permafrost: Status, variation and impacts. In: Zheng, D., Zhang, Q., Shao, H. (Eds.), Mountain geoecology and sustainable development of the Tibetan Plateau. Kluwer, Netherlands, pp. 113-137.

Zhou, X., 2001. China meadow. Science, Beijing. 